\title{
Design, Implementation and Analysis of Learner- Centered Guided In-Service Programme for Technical Teacher Education
}

\author{
http://dx.doi.org/10.3991/ijep.v4i2.3363 \\ Tiia Rüütmann, Hants Kipper \\ Tallinn University of Technology, Tallinn, Estonia
}

\begin{abstract}
The design of learner-centered guided in-service program for technical teacher education has been launched at Estonian Centre for Engineering Pedagogy at Tallinn University of Technology. The aim of the program has been facilitating the initial in-service teaching experience, involving mentoring, peer support and cognitive apprenticeship. The emphasis has been on teaching for knowledge application, including the choice of content and processes, motivation, reflection, problem-solving, choice of educational technology, effective teaching methods, teaching models and strategies - concepts, tools and procedures of the field of engineering, organized in ways enabling teachers to formulate real world problems, apply and solve them. The program has been implemented since 2012 and covers IGIP curriculum requirements. In the present article the designed program is described and analyzed.
\end{abstract}

Index Terms-guided in-service learning, continuing education, technical teacher, learner-centered education.

\section{INTRODUCTION}

To quote Theodore von Kármán [1], "Scientists discover the world that exists; engineers create the world that never was."

Engineering has never mattered more. The explosion of new information technologies, robotics, biotechnology, the increased blending of invention with scientific discovery: these are affecting powerfully every area of life. What engineers know and can do are critical resources for the society today.

According to Crawley, et al. [2] the purpose of engineering education is to provide the learning required by students to become successful engineers or knowledge workers - technical expertise, social awareness and knowledge of innovation. The combined set of knowledge, skills and attitudes is essential to strengthening productivity, entrepreneurship and excellence in the environment being based on technologically complex and sustainable products, processes and systems. Accordingly we improve the quality and nature of engineering education. Thus the objective of engineering education is to educate students who are ready to engineer, deeply knowledgeable of technical fundamentals.

Modern engineers meet the needs of the society. The task of higher education is to educate students to become effective modern engineers. Changes in society present challenges to engineering education. In order to educate not reactors to changes but, first and foremost, directors and executors of changes, it is important to promote de- velopment of the corresponding attitudes and skills in the students. These skills and attitudes are developed with the support of school, the key person being a teacher.

The task of engineering educators and technical teachers is to improve constantly the quality and nature of engineering education to meet these objectives. The present article introduces the newly designed program for contemporary education of technical teachers.

\section{DESIGN OF THE PROGRAM}

The design of learner-centered guided in-service program for technical teacher education, including initial teacher induction, has been launched at Estonian Centre for Engineering Pedagogy at Tallinn University of Technology since 2012. The aim of the design has been the structured STEM (science, technology, engineering, mathematics) teaching program facilitating the initial inservice teaching experience, involving mentoring, peer support and cognitive apprenticeship thus educating effective technical teachers, and teaching the art of teaching.

The emphasis has been on teaching for usable, applied knowledge, including the choice of content and processes, motivation, reflection and problem-solving, choice of technology, effective teaching methods, models and strategies - concepts, tools and procedures of the field of engineering, organized in ways enabling teachers to formulate problems and solve them.

As the required entrance qualification of candidates is Master degree in engineering or STEM, it is assumed that they have already acquired a complete knowledge and practical skills in the relevant field on high level afore. Engineers will acquire additionally knowledge and skills in teaching engineering subjects, both in theory and practice.

A successful program meets the needs of the contemporary further education sector, while guaranteeing academic standards appropriate to the teaching profession. The designed program for technical/STEM teachers should make scientifically-founded and practice-oriented teacher training possible, so that teachers can expect to build a deeper understanding of the principles, problems and solutions associated with teaching learners in technical institutions.

The designed program has been completed in 2012 in the amount of 31 ECTS credits (ECTS - European Credit Transfer System; 1 ECTS credit= 26 hours of workload, of which at least 12 should be attendance hours). The 
modular program consists of compulsory subjects (25 ECTS) and elective subjects (6 ECTS).

Compulsory subjects of the program are the following, covering the basic modules of IGIP curriculum:

- Engineering Pedagogy Science in Theory and Practice.

- Laboratory Didactics and Methodology.

- Educational Psychology and Sociology.

- Ethics and Multicultural Learning Environment.

- Rhetoric and Scientific Writing.

- Working with Projects: Curriculum Design.

- Educational Technology, Media and E-Learning.

Students may choose elective subjects from the list of subjects of engineering curricula of Tallinn University of Technology, or the electives may be designed specially for the learners at Estonian Centre for Engineering Pedagogy taking account of the needs and interests of the students.

The following elective subjects have already been specially designed for the students:

- Specialty Didactics for Teaching Welding and Engineering Graphics.

- Counseling in Educational Technology.

- Supervision of Practice and Mentoring at Institutions of Higher Education.

- Supervision of Practice and Mentoring at Vocational School.

- Teaching Practice and Mentoring.

In order to assure the high quality of the curriculum, the following five means for reinforcing the curriculum established at the macro-level have been used:

- Computers in instruction.

- Laboratory work.

- Individualised instruction.

- Self-access media.

- Project and research work.

Effective strategies and models have been worked out and are used for teaching thinking skills and capitalizing deep understanding in teaching STEM. Contemporary teaching methods, emphasizing conceptual understanding, adapted specially for engineering education have been widely tested and switched into described study program [3].

Students learn these attitudes through teacher modelling and by directly experiencing them in classroom activities. As students acquire these inclinations and develop critical thinking skills, their abilities to both learn and function effectively in the real world increase. Fortunately, teaching for thinking also increases STEM learner motivation.

\section{A. Interactive Teaching}

Once a teacher incorporates students' active breaks into the lecture, an interactive lecture is given, during which students are in some way actively interacting with the material for brief, controlled period of time. A teacher must carefully time-control the student-active breaks and follow actions, thus keeping students focused on the task.
At Estonian Centre for Engineering Pedagogy several tested interactive methods, suitable for teaching STEM are taught to the future technical and STEM teachers. The students practice holding and analyzing interactive lectures in seminars and workshops. The following most frequently used interactive teaching methods are taught during the study program [4]:

- Pair, compare and ask - additionally to the previous teaching method, students jot down questions on the lecture content, thus the material is reviewed and analyzed. Teacher answers the questions that students cannot answer themselves. Time: 3 minutes, plus time to answer students' questions;

- Periodic free-recall, with pare and compare optionstudents put away their lecture notes and write down the most important points of the lecture and questions they have, thus reviewing and processing reflectively the lecture content. Students may work individually or in pairs and answer each other's questions. Time 2-3 minutes, plus time for teacher to answer students' questions;

- Solve a problem - students solve a problem based on the lecture content it makes students to apply the lecture content, informing the teacher how they have understood. Time: 3 minutes for solving, 1-3 minutes to answer questions;

- Pair and discuss - students pair off and discuss an open ended question, in order to apply, analyze or evaluate the lecture material and synthesize it with the course material. Time: 3-10 minutes, plus 5-10 minutes for discussion;

- Think-pair-share - teacher gives students a question or a problem and asks them to think quietly, then to discuss with their neighbor and finally to share with the class;

- Students' teams achievement divisions - after a lecture students' teams receive a worksheet to discuss, complete and give oral presentation on results to others;

- Send a problem - each group of students write a question or a problem on a flashcard and write a right answer or a solution on the back. The card is passed to other groups which formulate their own answers and check them against that written on the back side, and write their alternative answers if necessary. At the end the original senders discuss alternative answers;

- The one-minute paper - students summarize the most important or useful points they learned from the lecture and questions that remained. It helps students think, absorb, digest, extrapolate and internalize new material moving it to long-term memory;

- The muddiest point - students give a quick response to a question: "What was not clear or confusing point in the lecture or topic?" They must identify and formulate what they did not understand. This method requires some higher-order thinking skills, ability to concentrate and pay attention;

- One-sentence summary - students summaries concisely, completely and creatively a large amount of information of the lecture or topic, thus developing abilities to synthesize, summaries and integrate ideas and information; 
PAPER

DESIGN, IMPLEMENTATION AND ANALYSIS OF LEARNER-CENTERED GUIDED IN-SERVICE PROGRAMME FOR...

- Application cards - after students have heard or read about an important principle, theory etc index cards are handed out to write down at least one possible real-world application for what has been learned. The method develops ability to think creatively, to apply principles to a new problem and situation, to draw interferences from observation.

Assessment of students' study outcomes has been up to dated, new assessment methods and criteria of study outcomes for all subjects have been switched into the program. Students participate actively in group works and analyze outcomes.

The education is completed after the final examination held by a commission of at least 3 members. Prerequisite of the final examination is timely submission of a teaching portfolio. The final examination consists of the written and oral examination. On the oral examination student must present an interactive micro-lesson, there is also discussion of the results of a written examination and an examination interview about the portfolio's components. The portfolio contains the complete written planning and performance of teaching sessions, teaching materials, used teaching methods, models and strategies, analysis on the teaching and students' learning styles and a subsequent self-analysis along with the analysis of students' feedback. The activities of a student during the presentation is monitored and registered according to the special protocol of engineering pedagogy. Precise criteria and requirements for holding the micro-lesson have been compiled.

The designed program is the only one in Estonia, providing both, continuing education for engineers in the field of teaching STEM and learner-centered guided inservice education for technical teachers. The program has been registered by Estonian Ministry of Education and Research and accredited by International Society for Engineering Education (IGIP). 31 ECTS credits is the sufficient amount for preparation of engineering educators who already have acquired afore the specialty qualification on Mater level in engineering, the fact being proved accordingly by the long-term studies by IGIP.

The designed program is based on the IGIP curriculum, the basic concept of which calls for a life-long continuous improvement process to excellent STEM teaching and learning. First 24 students have been accepted to the program in 2012 .

\section{DISCUSSION}

For teaching engineering effectively, teachers need a fundamental technical education, professional experience and a comprehensive teaching training. They should also gain greater confidence in their own skills and abilities through the use of an extended range of tools, techniques and activities. Centering education on professional teaching practice does not mean abandoning theoretical, technical and contextual engineering knowledge. It rather leads to teaching the knowledge needed for technical teachers more directly connected with engineering thinking and action related to the certain field of engineering being taught. Engineering problems usually require multiple iterations and integrated thinking in which the scientific, technological, contextual and ethical dimensions of engineering become routine aspects of professional thinking.
According to Sheppard et al. [5] cognitive apprenticeship consists of four fundamental key concepts:

- Modeling - providing representations of practice, representing expert performance that students ought to gain during their training. A key principle being teach what you want students to know or be able to do. Engineering educators therefore need to foster not the expertise of scientific research but the expertise of this science -using practice.

- Scaffolding - providing support for students' efforts to imitate the teacher's performance. Learners' performance is guided and supported to help them understand the important features of the performance.

- Coaching - giving deliberate, planned feedback and guidance that guides learners toward more competent imitation of expertise.

- Fading - removing the scaffolding as student performance strengthens to allow learners to exercise more discretion in their own thinking on higher levels towards competent performance.

In effect these principles suggest that robust learning of complex practices depends on experiences enabling learners to observe and imitate the knowledge and skills of experts, feedback guides the learners in making the activity increasingly their own. To learn a complex practice such as teaching engineering requires mostly learning by doing. This requires knowledge and skills - practice and feedback on the practice, followed by learner response to feedback and recurrent attention to the goals and procedures that make up the field. In the designed program all the fundamental key concepts of cognitive apprenticeship have been is use in the process of teaching and mentoring.

According to Jackson et al. [6], different ways of scaffolding may be used in teaching. Supportive scaffolding is support for doing the task. Scaffolding is provided alongside the task, offering advice and support, as the supportive scaffolding is faded, the expectation is that the learner has internalized the concepts. Guided scaffolding is provided through the practical tasks. Coaching and modeling scaffolding provide help and examples explaining the various modeling concepts. Reflective scaffolding is support for thinking about the task (planning, making predictions, evaluating), not changing the task but making the activity of reflection explicit by eliciting articulation from the learner. Intrinsic scaffolding supports the change of task itself by reducing the complexity of the task and focusing the learner's attention or by providing visualization of thinking about the concept. Ideally scaffolding should support more gradual fading - as the scaffold fades, the task is changed, but associations should remain helping the learner to progress from simpler, more structured or more concrete tasks to variations, in which more complexity of abstractness is introduced. Scaffolding in teaching engineering $s$ of high importance as it is based on STEM educational design.

The designed program takes account of Lang \& Evans [7] recommendation to focus attention on teaching following thinking operations, suitable for education of engineering teachers:

- Comparing - look for similarities and differences by observing details, find and sort similarities, search and sort differences, and summarise in a list; 
- Observing - observing should lead to more accurate data on which to base conclusions, and to greater understanding;

- Classifying - examining and assortment of items and sorting them into related groups. Each group is given a name, students can process data mentally and organise them systematically. Classifying requires three steps: examining data, creating categories, and placing items in categories;

- Hypothesising - students are to come up with a variety of possible explanations for a question, problem, situation, thus identifying alternative possibilities and deciding which have the most credibility;

- Criticising - ask students to evaluate, make judgements and offer opinions to sharpen their sense of what is desirable or undesirable, high or low quality, significant or trivial;

- Looking for assumptions - taking something for granted or assume - being probably true or probably false thus students can learn to identify assumptions. Learning to differentiate between what is assumed to be true and what is observable fact is at the heart of logical reasoning;

- Collecting and organising data - requires several skills: locating information, examining the data and selecting relevant to the inquiry, developing procedures that allow data to be assembled, organising data;

- Summarising - requires condensing and distilling the core message from a piece of work. Students must state the main ideas, differentiating between what is important and what may be left out, thus increasing students' abilities to understand;

- Coding - communicate ideas in "shorthand", as a thinking operation, coding is a system for pointing out through patterns or expressions;

- Interpreting - explaining the meaning, skilful interpretation increases meaning and understanding.

Facts and information are the important raw materials for thinking. Knowing how and having the skills to access and use these to think is at least as important for STEM teachers. It is important to use higher level thinking and ask higher level questions in order to evoke critical creative thinking.

Attention is also paid to self-directed learning, engaging students actively to acquire higher-order learning skills, helping students to construct their own understanding and meaning and help them to reason, problem-solve, analyze, evaluate and think critically about the content.

\section{A. Solving Problems and Problem Solving}

Although the deductive approach to teaching in engineering science and advanced technical courses might seem a clean and organized way of introducing new material, it doesn't encourage students to involve actively in their learning process.

Faculty seem to feel obliged to teach as much of theory and principles as possible. However, simply transmitting knowledge through lecture does not guarantee students' comprehension or their ability to apply it or learn to analyze. Students cannot convert separate principles into solutions they need opportunities for processing the information in order to implement knowledge.

Problem solving demands understanding. Students need to gain deep understanding in basic principles and the ability to organize and restructure them. Students learn with understanding when they develop a conceptual framework for the facts, transferring and applying what they have learned to other situations, thus developing professional competence.

Analysis is critical to problem solving. There are an infinite number of possibilities to solve a problem - one just has to find the most efficient way. Students need to rehears Analysis.

Bloom's Taxonomy has stood the test of time. In Revised Bloom's taxonomy The Cognitive Process Dimension across the top of the grid consists of six levels that are defined as [8]:

- Remembering - retrieving, recognizing, and recalling relevant knowledge from long-term memory.

- Understanding - constructing meaning from oral, written, and graphic messages through interpreting, exemplifying, classifying, summarizing, inferring, comparing, and explaining.

- Applying - carrying out or using a procedure through executing, or implementing in a new way.

- Analyzing - breaking material into constituent parts, determining how the parts relate to one another and to an overall structure or purpose through differentiating, organizing, and attributing.

- Evaluating - making judgments based on criteria and standards through checking and critiquing.

- Creating - putting elements together to form a coherent or functional whole; reorganizing elements into a new pattern or structure through generating, planning, or producing.

Engineering faculty seems to feel compelled to teach only across the three lower levels - remembering, understanding and applying. But it is critical especially in real engineering to distinguish between different paths, analyze, evaluate, and create. The designed engineering program demonstrates that its graduates have:

- Ability to apply knowledge of STEM (science, technology, engineering and mathematics).

- Ability to design and conduct experiments, as well as to analyze and interpret data.

- Ability to design a system, component, or process to meet desired needs.

- Ability to function on multi-disciplinary teams.

- Ability to identify, formulate and solve engineering problems.

- Understanding of professional and ethical responsibility.

- Ability to communicate effectively.

- Broad education necessary to understand the impact of engineering solutions in a global and societal context.

- Recognition of the need for, and an ability to engage in life-long learning.

- Knowledge of contemporary issues. 
- Ability to use the techniques, skills, and modern engineering tools necessary for engineering practice.

The designed program teaches engineering teachers to use complex real-world problems in order to provide context for course material. Thus the student groups have to learn to:

- Define the problem.

- Build hypotheses to initiate the solution process.

- Identify what is known, what must be determined, and how to proceed.

- Generate possible solutions and decide on the best one.

- Complete the best solution and defend it.

- Reflect on lessons learned.

\section{B. Inductive Teaching}

The dominant teaching model in engineering is deductive, where a teacher takes full control of the transmission of knowledge - this model regards a teacher as an expert and students as a group of novices. The process of learning, thinking, and doing sends a powerful message that students receive as information about how engineers work. Having no other experience, they take the classroom to represent profession. Numerous textbook problems they have to solve do not sufficiently challenge students to move to a deeper level understanding and skill of analysis that helps towards critical thinking. Exams generally assess students' skill in using engineering tools and students are expected to show technical skill in applying mathematical formula to a given problem. Learning to use concepts to analyse real-world problems is an important goal in teaching engineering, but students have very little opportunity to develop these skills today.

Inductive teaching is one way to help students learn to use the fundamental concepts for problem solving teacher focuses on cases that students could work on to help them develop an understanding of the phenomenon that these cases represent before a principle is introduced.

A teacher might begin with a problem, such as how to hold a $2 \mathrm{~kg}$ weight using a piece of paper and paper clips and ask the students to figure out the fundamental elements which are critical to the problem. Based on their knowledge and experience, students attempt to explore possible cases, developing a sense of awareness of the relevant key elements - load, stress and strength. They begin their concept-formation based on the phenomenon observed. Teacher introduces new cases and along with students identifies their fundamental elements, using formulas, equations, graphs or diagrams as tools in helping students refine their concept formation.

We should recognize that students learn best when they perceive a need to know the material being taught. We recommend to start with realistic complex problems, let students establish what they know and what they need to find out, and then guide them in finding it out by providing a combination of resources (which may include interactive mini-lectures and integrated hands-on or simulated experiments) and guidance on performing library and Internet research. This is inductive teaching and has a number of variations, including problem-based learning, project-based learning, guided inquiry, discovery learning, and just-in-time teaching [9].
The Inductive Model is designed to help students reach two types of learning objectives:

- For students to acquire deep and thorough understanding of specific and well-defined topics.

- To develop students' critical thinking abilities. Students try to find patterns in the new information and with the teacher's guidance they construct a thorough understanding of the topics and learn to make and assess conclusions based on evidence.

Inductive teaching encourages students to think in real terms and potential of students to be more reflective about their own learning, as the learning experience becomes more iterative and less linear. Although the inductive model can be messy and challenging, its impact on student learning can be enormous. The designed program concentrates on inductive teaching.

\section{Analysis of the Feedback of Learners}

The first 24 students graduated the described program in $2013,52 \%$ of them were male and $48 \%$ female. A research of feedback of graduated students was carried out.

A special questionnaire consisting of 30 questions was compiled. The aim of the research was to evaluate the quality of the curriculum and the quality of teaching in order to improve technical teacher education. All the students participating in the research had acquired academic higher education in different engineering specialties on at least the Master level afore attending the above described program.

Evaluation of the program and subjects in the feedback included a set of questions regarding whether subjects offer interesting and novel subject matter and up-to-date information; whether high quality learning materials are available; the connection of theory with practice; a contemporary learning environment; clear and obtainable learning objectives; the strength of purpose of the subjects and curriculum; consideration of the prior knowledge and different learning styles of learners; the use of contemporary effective teaching methods; e-learning, active learning, learner centered teaching etc.

Students were asked to answer using a scale of 6 points (from " 0 - absolutely do not agree" to " 5 - fully agree").

The subjects of the curriculum and syllabi were evaluated highly, the average score given by the students being 4.75 of the maximum 5. The highest evaluation was given to the subject Engineering Pedagogy Science (4.82 of possible maximum 5), Educational Psychology and Sociology (4.75), Rhetoric and Scientific Writing (4.61), Curriculum Development and Design (4.54), Teaching Technology, Media and E-Learning (4.41), Ethics and Intercultural Relations (4.36), Laboratory Didactics and Methodology (4.53).

The electives, specially designed for the students were also evaluated highly: Specialty Didactics for Teaching Welding and Engineering Graphics $(4,90)$, Counseling in Educational Technology $(4,86)$, Supervision of Practice and Mentoring at Institutions of Higher Education (4,79), Supervision of Practice and Mentoring at Vocational School (4,88), Teaching Practice and Mentoring (4,92).

Students agreed with the proper structure of the curriculum and the useful syllabi (4.65), that subjects offer interesting and novel subject matter $(4,81)$, up-to-date information $(4,92)$, that high quality learning materials were 
available $(4,76)$; the connection of theory with practice $(4,88)$; a contemporary learning environment $(4,90)$; clear and obtainable learning objectives $(4,92)$; the strength of purpose of the subjects and curriculum $(4,78)$; consideration of the prior knowledge and different learning styles of learners $(4,87)$; the use of contemporary effective teaching methods $(4,69)$; e-learning $(4,62)$, active learning $(4,79)$, learner centered teaching $(4,94)$.

Lots of proposals were made (to mention but a few): there could be more psychological and pedagogical subjects included in the curriculum, the list of elective subjects could be longer. The Statute of the curriculum of TUT prescribes the proportion of electives in the curriculum; increasing of the amount of electives could provide students with a wider array of possible selections, including subjects providing non-technical competences.

$90 \%$ of the students were eager to study additional engineering speciality subjects in order to update their knowledge.

\section{CONCLUSIONS}

Professional engineering teaching is both, an art and science. Like artists, good engineering teachers make decisions from technical and creative perspectives, they know when and in what way to apply their skills, constantly analyzing and making decisions. Teachers develop their subject matter using planned and tuned lessons reflecting an understanding of many different teaching techniques, applying each technique to gain the desired result. They are aware of what they are doing and how their actions affect learners. They make choices and decisions thus affecting skills of their students. Implicit within the concept of decision making is the notion of responsibility. Teachers who take responsibility for decision making develop instructional plan geared for success.

The aim of the design of learner-centered guided inservice program has been the structured program facilitating the initial in-service teaching experience, involving mentoring, peer support and cognitive apprenticeship, thus educating effective technical teachers and teaching the art of teaching. The feedback given by first graduates of the program has confirmed that the goals have been achieved. The feedback motivates the designers of the program to move further in the design process and start with the design of the curriculum on master level for technical and STEM teachers in Estonia.

\section{REFERENCES}

[1] Von Kármán, T. In: Mackay A.,L., Dictionary of Scientific Quotations, London, 1994

[2] Crawley E., Malmqvist J., Östlund S., Brodeur D., Rethinking Engineering Education. The CDIO Approach., Springer, 2007

[3] Kipper, H.; Rüütmann, T. Contemporary Teaching Strategies and Models Capaciating Critical Thinking and Deep Understanding in Teaching Engineering. Proceedings of the Joint International IGIP-SEFI Annual Conference 2010. 463 - 464. Brussel, Belgium: SEFI, 2010

[4] Rüütmann, T.; Vanaveski, J. Contemporary Teaching Methods as the Basis of the Curriculum for Technical Teacher Training at Tallinn University of Technology. In: 38th IGIP SYmposium - Ouality and Quantity of Engineering Education, 6-9 September 2009, Graz Austria. 139-142, 2009.

[5] Sheppard S.D., Macatangay K., Colby A., Sullivan W.M. Educating Engineers. Designing for the Future of the Field, Jossey-Bass, 2009.

[6] Jackson S.L., Krajcik J., Soloway E., The Design of Guided Learner-Adaptable Scaffolding in Interactive Learning Environments, University of Michigan, 1999.

[7] H. R. Lang, D. N. Evans, Models, Strategies and Methods for Effective Teaching, Pearson Education Inc, 2006.

[8] Anderson, L. W., \& Krathwohl, D. R. (Eds.). A taxonomy for learning, teaching and assessing: A revision of Bloom's Taxonomy of educational objectives: Complete edition, New York: Longman, 2001.

[9] M.J. Prince, R.M. Felder. Inductive Teaching and Learning Methods: Definitions, Comparisons, and Research Bases, Journal of Engineering Education, 95(2), 123-138, 2006. http://dx.doi.org/10.1002/j.2168-9830.2006.tb00884.x

\section{AUTHORS}

Tiia Rüütmann and Hants Kipper are with Tallinn University of Technology, Tallinn, Estonia.

This article is an extended and modified version of a paper presented at the ICL2013 Special Session "Talking about Teaching 2013" (TaT'13), held from 25 to 27 September 2013 at Kazan National Research Technological University, in Kazan, Russia. Submitted 18 November 2013. Published as re-submitted by the authors 17 March 2014. 